\title{
Performed Exclusion Criterion
}

National Cancer Institute

\section{Source}

National Cancer Institute. Performed Exclusion Criterion. NCI Thesaurus. Code C93367.

A characteristic or requirement that disqualifies a subject from participation in a study. 